\title{
Dietary patterns and metabolic syndrome factors in a non-diabetic Italian population
}

\author{
Maria Léa Corrêa Leite ${ }^{1, *}$ and Alfredo Nicolosi ${ }^{1,2}$ \\ 'Department of Epidemiology and Medical Informatics, Institute of Biomedical Technologies, National Research \\ Council (CNR), Via Fratelli Cervi 93, 20090 Segrate, Milan, Italy: ${ }^{2}$ Gertrude H. Sergievsky Center, School of \\ Public Health, Columbia University, New York, NY, USA
}

Submitted 12 October 2007: Accepted 18 November 2008: First published online 15 January 2009

\begin{abstract}
Objective: To examine the relationship between dietary patterns and metabolic syndrome.

Design: Population-based cross-sectional study. The K-means clustering method was used to identify dietary patterns and logistic regression models were used to compare the adjusted prevalence rates of metabolic syndrome factors, stratifying by obesity status.

Setting: The 1992-3 Italian Bollate Eye Study, a population-based survey carried out in the town of Bollate (Milan), Italy.

Subjects: A total of 1052 non-diabetic Italian subjects, 527 men and 525 women, aged 42-74 years.

Results: Five dietary clusters were identified: common, animal products, starch, vegetal/fat and vitamin/fibre. After adjusting for potential confounders, the starch group showed the highest prevalence of metabolic syndrome $(36 \%)$ followed by the animal products group (30\%); the vitamin/fibre (20\%) and vegetal/fat groups (19\%) showed the lowest prevalence. The starch group had more dyslipidaemia (higher TAG and lower HDL cholesterol levels) and the animal products group had a higher prevalence of impaired fasting glucose. The vitamin/fibre group had the lowest prevalence of abdominal obesity. The beneficial effect of the vegetal/ fat and vitamin/fibre dietary patterns seemed stronger among the obese.

Conclusions: Our results confirm the deleterious effect of a very-low-fat, highcarbohydrate diet and also of high intakes of animal products. The consumption of a diet high in vegetal fats or rich in fruits and vegetables is associated with a healthier metabolic profile. Reducing obesity is essential to prevent metabolic syndrome, but even among the obese dietary habits are important for preserving healthy lipid and glycaemic profiles.
\end{abstract}

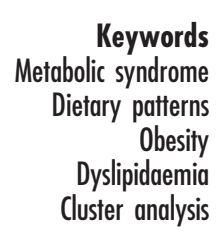

Metabolic syndrome indicates a group of markers abdominal obesity, atherogenic dyslipidaemia, increased blood pressure and high plasma glucose levels - whose presence points to a very high risk of developing diabetes or CVD. These outcomes can be effectively prevented by early syndrome management, particularly including lifestyle modifications ${ }^{(1)}$.

It is widely recognised that a healthy balanced diet is one of the principal elements in the prevention of diabetes and CVD, but it is still unclear which dietary pattern is the most beneficial for the successful management of metabolic syndrome and its complications, especially regarding the proportion and type of carbohydrates and fat ${ }^{(2-4)}$. Furthermore, the possible influence of conditions such as overweight and obesity on the relationship between diet and the metabolic syndrome needs to be evaluated ${ }^{(5)}$.
We used the database of the Italian Bollate Eye Study ${ }^{(6-8)}$ to examine the relationships between dietary patterns and metabolic syndrome factors in an adult population.

\section{Methods}

We used data from the 1992-3 Italian Bollate Eye Study, which was designed to investigate the prevalence and risk factors of major eye diseases in a population consisting of a random sample of all individuals aged 40-74 years drawn from the residents' list of the town of Bollate (Milan, Italy). A letter was sent to the sampled subjects (2882 individuals) to explain the study objectives and invite their participation, after which each one was contacted by phone in order to 
collect consent and schedule an appointment at the local hospital's outpatient clinic. The project was approved by the National Research Council.

The hospital visit was attended by 1691 subjects (59\% of the original population sample), and included an interview concerning medical and family history, the past or current use of drugs, lifestyle habits, a $24 \mathrm{~h}$ diet recall and an FFQ, and anthropometric (height, weight, body circumferences and skinfold thicknesses) and blood pressure measurements (both arms). The FFQ was based on 166 items arranged into thirteen categories (number of items in parentheses): (i) bread/cereal products ( $n$ 23); (ii) eggs, meats, cured pork ( $n$ 28); (iii) fish ( $n$ 8); (iv) dairy products ( $n$ 8); (v) cheese ( $n$ 10); (vi) vegetables ( $n$ 26); (vii) oil/sauces/condiments ( $n$ 17); (viii) fruits ( $n$ 18); (ix) sweets ( $n$ 9); (x) beverages/coffee ( $n$ 6); (xi) alcohol ( $n 7)$; (xii) sugar ( $n 3$ ); and (xiii) miscellaneous ( $n 3$ ). The questionnaire was quantitative (a modification of Willett's questionnaire for the Nurses' Health Study ${ }^{(9)}$ ), with the quantities of food being assessed by means of photographs of food portions. A blood sample, drawn during fasting, was collected for laboratory tests (haematology, glycaemia, lipids).

The subjects were classified as non-smokers, ex-smokers or current smokers; and as teetotallers or consumers of $\leq 30$ or $>30 \mathrm{~g}$ alcohol/d. Education was classified at three levels: primary school or less; high school; further education. Physical activity was assessed on the basis of the time spent watching television, walking/cycling and practising sport.

Nutrient intake was calculated using the food composition database compiled for epidemiological studies in Italy ${ }^{(10)}$, and cluster analysis was used to assess dietary patterns. In order to capture the qualitative aspects of the dietary habits of our subjects more accurately, we adjusted the measures of nutrient consumption by total energy intake using the residual method ${ }^{(11)}$, and the energyadjusted nutrient intakes were standardised in order to avoid any influence of different units of measurement. Inspection of the distributions of the energy-adjusted nutrients showed that no one among them was seriously skewed, so we standardised the variables without transformation. The partitioning clustering method (the Kmeans algorithm) ${ }^{(12)}$ was used to separate the subjects into non-overlapping subgroups based on similarities in their nutrient consumption profiles. The K-means algorithm is a simple, iterative procedure which is based on the definition of a point (centroid) in the space of records which represents an average location of the particular cluster. Thus, the coordinates of this point are averages of nutrient intakes of all subjects who belong to the cluster. This algorithm has as an input a predefined number $k$ of clusters and the proper way to choose the right number of clusters is to try with different values for $k$. In principle, the best cluster solution will exhibit the smallest intra-cluster distances and largest inter-cluster distances.
Distances between clusters increase as the number of clusters increases, but high values of $k$ could result in non-workable small cluster size.

Metabolic syndrome was diagnosed on the basis of the National Cholesterol Education Program Adult Treatment Panel III criteria ${ }^{(13)}$, which define it as the presence of three or more of the following risk determinants: (i) an increased waist circumference $(>102 \mathrm{~cm}$ in men and $>88 \mathrm{~cm}$ in women); (ii) high TAG level ( $\geq 150 \mathrm{mg} / \mathrm{dl}$ ); (iii) low HDL cholesterol (HDL-C) level $(<40 \mathrm{mg} / \mathrm{dl}$ in men and $<50 \mathrm{mg} / \mathrm{dl}$ in women); (iv) increased blood pressure $(\geq 130 / \geq 85 \mathrm{mmHg}$ ); and (v) impaired fasting glucose level $(\geq 100 \mathrm{mg} / \mathrm{dl})$, as subsequently established in accordance with the American Diabetes Association's revised definition of impaired fasting glucose $e^{(14)}$.

Complete anthropometric, lifestyle, laboratory and dietary data were obtained relating to 1163 subjects. We excluded 111 subjects with diabetes (plasma glucose $>125 \mathrm{mg} / \mathrm{dl}$ and/or self-referred diabetes) whose diet may have been modified after the onset of their disease.

Logistic regression models were used to compare the prevalence rates of the individual metabolic syndrome disorders across the different dietary pattern groups, adjusting for age, gender, education, smoking, alcohol consumption and the degree of physical activity as assessed on the basis of the frequency of practising sport and walking/cycling and the time spent watching television. These prevalence rates were calculated for all of the subjects as a whole and after stratifying by obesity status as defined by BMI values. Odds ratios were used to quantify and test the association between metabolic syndrome and the dietary patterns described by the clusters, accompanied by their $95 \%$ confidence intervals ${ }^{(15)}$.

The data were analysed using the SPSS for Windows statistical software package version $10 \cdot 0 \cdot 7$ (SPSS Inc. Chicago, IL, USA).

\section{Results}

The characteristics and metabolic profiles concerning the 1052 non-diabetic subjects ( 527 men and 525 women) are shown in Table 1.

\section{Dietary patterns}

Table 2 shows the results of the dietary data analysis. The last four columns show the overall daily mean intake of the twenty-seven nutrients entered into the cluster analysis for men and women. On the whole, the eating habits of our population combined some typical elements of the Mediterranean diet, such as a high intake of olive oil, fruit and vegetables, with those of a 'wealthy' diet, such as a high intake of processed meats and refined-grain products (food intake data not shown). These characteristics were reflected - at nutrient level - in a generally high intake of unsaturated fats, vitamins and minerals, as well 
Table 1 Characteristics and metabolic profile of the study population: individuals aged $40-74$ years, Bollate (Milan, Italy), 1992-3

\begin{tabular}{|c|c|c|c|}
\hline Variable & Statistic & Men $(n 527)$ & Women $(n 525)$ \\
\hline \multirow[t]{2}{*}{ Age (years) } & Mean & $58 \cdot 1$ & $56 \cdot 0$ \\
\hline & Range & $43-74$ & $42-74$ \\
\hline \multirow[t]{2}{*}{ BMI $\left(\mathrm{kg} / \mathrm{m}^{2}\right)$} & Mean & $26 \cdot 8$ & $26 \cdot 9$ \\
\hline & SD & $3 \cdot 4$ & $4 \cdot 5$ \\
\hline \multicolumn{4}{|l|}{ Education } \\
\hline Primary school or less & $\%$ & $50 \cdot 0$ & $64 \cdot 6$ \\
\hline High school & $\%$ & $26 \cdot 7$ & $23 \cdot 8$ \\
\hline Further education & $\%$ & $23 \cdot 3$ & $11 \cdot 6$ \\
\hline \multicolumn{4}{|l|}{ Television watching } \\
\hline$<2 \mathrm{~h} / \mathrm{d}$ & $\%$ & $12 \cdot 0$ & $15 \cdot 6$ \\
\hline $2-3 \mathrm{~h} / \mathrm{d}$ & $\%$ & $65 \cdot 5$ & $58 \cdot 2$ \\
\hline$\geq 4 \mathrm{~h} / \mathrm{d}$ & $\%$ & $22 \cdot 5$ & $26 \cdot 2$ \\
\hline Practising any sport & $\%$ & $17 \cdot 6$ & $17 \cdot 1$ \\
\hline Walking and/or cycling for at least $15 \mathrm{~min} / \mathrm{d}$ & $\%$ & $72 \cdot 2$ & $70 \cdot 7$ \\
\hline \multicolumn{4}{|l|}{ Smoking } \\
\hline Non-smokers & $\%$ & $27 \cdot 8$ & $71 \cdot 4$ \\
\hline Ex-smokers & $\%$ & $37 \cdot 7$ & $8 \cdot 4$ \\
\hline Current smokers & $\%$ & $34 \cdot 5$ & $20 \cdot 2$ \\
\hline \multicolumn{4}{|l|}{ Alcohol intake } \\
\hline Teetotallers & $\%$ & $13 \cdot 6$ & $47 \cdot 7$ \\
\hline$\leq 30 \mathrm{~g} / \mathrm{d}$ & $\%$ & $37 \cdot 3$ & $42 \cdot 8$ \\
\hline$>30 \mathrm{~g} / \mathrm{d}$ & $\%$ & $49 \cdot 1$ & $9 \cdot 5$ \\
\hline \multirow[t]{2}{*}{ Waist circumference $(\mathrm{cm})$} & Mean & $96 \cdot 6$ & $87 \cdot 2$ \\
\hline & SD & $10 \cdot 3$ & $11 \cdot 9$ \\
\hline$>102 \mathrm{~cm}($ men) $/>88 \mathrm{~cm}$ (women) & $\%$ & $25 \cdot 2$ & $44 \cdot 1$ \\
\hline \multirow[t]{2}{*}{ TAG $(\mathrm{mg} / \mathrm{dl})$} & Mean & $148 \cdot 8$ & $109 \cdot 4$ \\
\hline & SD & $95 \cdot 4$ & $58 \cdot 8$ \\
\hline$\geq 150 \mathrm{mg} / \mathrm{dl}$ & $\%$ & $36 \cdot 7$ & $16 \cdot 2$ \\
\hline \multirow[t]{2}{*}{ HDL cholesterol (mg/dl) } & Mean & $51 \cdot 5$ & $64 \cdot 2$ \\
\hline & SD & $13 \cdot 8$ & $14 \cdot 3$ \\
\hline$<40 \mathrm{mg} / \mathrm{dl}$ (men)/<50 mg/dl (women) & $\%$ & $16 \cdot 3$ & $13 \cdot 5$ \\
\hline \multirow[t]{2}{*}{ Systolic blood pressure $(\mathrm{mmHg})$} & Mean & $138 \cdot 5$ & $135 \cdot 2$ \\
\hline & SD & $16 \cdot 8$ & $19 \cdot 3$ \\
\hline \multirow{3}{*}{ Diastolic blood pressure $(\mathrm{mmHg})$} & $\%$ & $71 \cdot 6$ & $61 \cdot 0$ \\
\hline & Mean & $85 \cdot 2$ & $83 \cdot 7$ \\
\hline & SD & $8 \cdot 8$ & $8 \cdot 7$ \\
\hline$\geq 85 \mathrm{mmHg}$ & $\%$ & $53 \cdot 2$ & $44 \cdot 7$ \\
\hline \multirow[t]{2}{*}{ Fasting glucose (mg/dl) } & Mean & $93 \cdot 4$ & $89 \cdot 7$ \\
\hline & SD & $12 \cdot 0$ & $10 \cdot 9$ \\
\hline $100-125 \mathrm{mg} / \mathrm{dl}$ & $\%$ & $27 \cdot 3$ & $19 \cdot 4$ \\
\hline
\end{tabular}

as of cholesterol and $\mathrm{Na}$. As a preliminary analysis of the men and women separately did not reveal any betweengender differences in the resulting clusters, we subsequently pooled the data, which also had the advantage of increasing statistical efficiency. The criteria chosen for determining the number of clusters resulted from a balance between the evaluation of the distances between final cluster centres (greater distances correspond to greater dissimilarities) and the cluster sizes. We started inputting $k=2$ and proceeded by adding one cluster at the time. The solution chosen was a compromise between the increase in the distances between cluster centres and an acceptable reduction in cluster sizes. The most workable and interpretable solution was the five clusters result, which seemed to capture the nutrient intake patterns most appropriately.

1. Common pattern: This was the largest group, and the final cluster centres were close to the overall mean expected intakes. Thus their characteristics are generally similar to those above described. This diet was moderately low in fat, which accounted for $26.9 \%$ of energy (\%E), but relatively high $(12 \cdot 1 \% \mathrm{E})$ in MUFA. Its carbohydrate content was slightly high $(57 \cdot 7 \% \mathrm{E})$. Men and women in this cluster had the lowest mean daily total energy intake, 11792.6 and $9970.5 \mathrm{~kJ}$, respectively.

2. Animal products pattern: The people in this group had the highest consumption of meat, eggs and dairy products. Their diet was high in protein $(20.0 \% \mathrm{E})$, particularly from animal sources $(14 \cdot 8 \% \mathrm{E})$. They consumed relatively more fats $(31 \cdot 1 \% \mathrm{E})$, particularly of the saturated type $(11.9 \% \mathrm{E})$. This diet was the richest in cholesterol, $\mathrm{P}, \mathrm{Zn}$, complex $\mathrm{B}$ vitamins and vitamin D; it was also low in carbohydrates $(48 \cdot 9 \% \mathrm{E})$.

3. Starch pattern: The diet of the people in this, the smallest group was the richest in starch, vegetal proteins and $\mathrm{Na}$, and the poorest in fats, vitamins and minerals. It was very high in carbohydrates $(68 \cdot 8 \% \mathrm{E})$ and very low in fat $(17 \cdot 3 \% \mathrm{E})$, and characterised 
Table 2 Nutrient intake patterns ${ }^{\star}$ and nutritional features of the five groups identified by cluster analysist among individuals aged $40-74$ years, Bollate (Milan, Italy), 1992-3

\begin{tabular}{|c|c|c|c|c|c|c|c|c|c|}
\hline & \multirow{2}{*}{\multicolumn{5}{|c|}{ Cluster }} & \multicolumn{4}{|c|}{ Overall daily intake } \\
\hline & & & & & & \multicolumn{2}{|c|}{ Men } & \multicolumn{2}{|c|}{ Women } \\
\hline & Common & Animal products & Starch & Vegetal/fat & Vitamin/fibre & Mean & SD & Mean & SD \\
\hline \multicolumn{10}{|l|}{ Nutrients } \\
\hline Animal protein $(\mathrm{g})$ & - & +++ & ---- & - & - & $77 \cdot 5$ & $25 \cdot 5$ & $70 \cdot 4$ & $25 \cdot 8$ \\
\hline Vegetal protein (g) & + & - & +++ & -- & + & $43 \cdot 2$ & $8 \cdot 8$ & $39 \cdot 5$ & $10 \cdot 0$ \\
\hline Animal fat $(g)$ & - & ++ & ---- & ++ & - & $57 \cdot 2$ & $21 \cdot 9$ & $50 \cdot 9$ & $18 \cdot 9$ \\
\hline Vegetal fat (g) & - & - & - & +++ & - & $38 \cdot 4$ & $21 \cdot 1$ & $35 \cdot 2$ & $16 \cdot 5$ \\
\hline Saturated fat $(\mathrm{g})$ & - & ++ & ---- & ++ & - & $33 \cdot 3$ & $11 \cdot 1$ & $30 \cdot 1$ & $10 \cdot 2$ \\
\hline Monounsaturated fat (g) & - & + & ---- & +++ & - & $41 \cdot 5$ & $14 \cdot 9$ & $36 \cdot 8$ & $10 \cdot 9$ \\
\hline Polyunsaturated fat $(\mathrm{g})$ & - & - & --- & +++ & - & $14 \cdot 5$ & $6 \cdot 3$ & $13 \cdot 1$ & $5 \cdot 2$ \\
\hline Cholesterol (mg) & - & ++ & --- & + & - & $462 \cdot 3$ & $155 \cdot 8$ & $425 \cdot 6$ & $157 \cdot 0$ \\
\hline Starch (g) & + & - & ++++ & - & -- & $250 \cdot 8$ & $74 \cdot 6$ & $205 \cdot 2$ & $72 \cdot 1$ \\
\hline Sugar (g) & + & - & -- & -- & +++ & $174 \cdot 7$ & $70 \cdot 1$ & $184 \cdot 2$ & $70 \cdot 4$ \\
\hline Fibre $(\mathrm{g})$ & - & - & - & -- & +++ & $37 \cdot 2$ & $11 \cdot 1$ & $38 \cdot 8$ & $12 \cdot 4$ \\
\hline $\mathrm{Fe}(\mathrm{mg})$ & - & + & - & -- & ++ & $22 \cdot 0$ & $5 \cdot 5$ & $18 \cdot 6$ & $4 \cdot 4$ \\
\hline $\mathrm{Ca}(\mathrm{mg})$ & - & ++ & -- & - & + & $1283 \cdot 7$ & $531 \cdot 2$ & $1303 \cdot 7$ & $503 \cdot 2$ \\
\hline $\mathrm{Na}(\mathrm{mg})$ & - & + & ++ & - & - & $5567 \cdot 0$ & $2267 \cdot 3$ & $5258 \cdot 3$ & $2119 \cdot 8$ \\
\hline $\mathrm{K}(\mathrm{mg})$ & - & + & -- & -- & +++ & $5981 \cdot 2$ & $1576 \cdot 5$ & $5922 \cdot 2$ & $1647 \cdot 2$ \\
\hline$P(m g)$ & - & +++ & --- & -- & + & $1996 \cdot 6$ & $446 \cdot 2$ & $1837 \cdot 6$ & $389 \cdot 7$ \\
\hline $\mathrm{Zn}(\mathrm{mg})$ & - & +++ & --- & - & + & $17 \cdot 4$ & $3 \cdot 5$ & $15 \cdot 7$ & $3 \cdot 4$ \\
\hline Thiamin (mg) & - & + & --- & -- & +++ & $1 \cdot 5$ & 0.3 & $1 \cdot 5$ & $0 \cdot 3$ \\
\hline Riboflavin (mg) & - & ++ & --- & -- & ++ & $2 \cdot 2$ & 0.6 & $2 \cdot 3$ & $0 \cdot 7$ \\
\hline Niacin (mg) & - & ++ & -- & -- & + & $29 \cdot 0$ & $6 \cdot 6$ & $26 \cdot 0$ & $6 \cdot 4$ \\
\hline Vitamin C (mg) & - & - & -- & -- & +++ & $265 \cdot 9$ & $144 \cdot 7$ & $321 \cdot 2$ & $179 \cdot 1$ \\
\hline Vitamin $B_{6}(\mathrm{mg})$ & - & ++ & --- & -- & +++ & $3 \cdot 2$ & 0.7 & $3 \cdot 0$ & 0.7 \\
\hline Folic acid $(\mu \mathrm{g})$ & - & + & -- & -- & +++ & $444 \cdot 3$ & $118 \cdot 7$ & $472 \cdot 5$ & $144 \cdot 4$ \\
\hline Vitamin A $(\mu \mathrm{g})$ & - & + & --- & -- & +++ & $1431 \cdot 3$ & $621 \cdot 8$ & $1660 \cdot 6$ & $742 \cdot 3$ \\
\hline$\beta$-Carotene $(\mu \mathrm{g})$ & - & - & -- & -- & +++ & $6445 \cdot 6$ & $3401 \cdot 5$ & $7929 \cdot 4$ & $4240 \cdot 2$ \\
\hline Vitamin $\mathrm{E}(\mathrm{mg})$ & - & - & --- & + & ++ & $12 \cdot 3$ & $4 \cdot 4$ & $12 \cdot 7$ & $4 \cdot 4$ \\
\hline Vitamin D $(\mu \mathrm{g})$ & - & ++ & -- & - & - & $4 \cdot 2$ & $2 \cdot 5$ & $3 \cdot 6$ & $2 \cdot 2$ \\
\hline \multicolumn{10}{|l|}{ Percentage of energy from } \\
\hline Proteins & $15 \cdot 4$ & $20 \cdot 0$ & $13 \cdot 9$ & $14 \cdot 5$ & $15 \cdot 9$ & & & & \\
\hline Animal protein & $9 \cdot 3$ & $14 \cdot 8$ & $6 \cdot 2$ & $9 \cdot 7$ & $9 \cdot 8$ & & & & \\
\hline Vegetal protein & $5 \cdot 9$ & $5 \cdot 2$ & $7 \cdot 7$ & $4 \cdot 8$ & $6 \cdot 1$ & & & & \\
\hline Fat & $26 \cdot 9$ & $31 \cdot 1$ & $17 \cdot 3$ & $38 \cdot 4$ & $25 \cdot 2$ & & & & \\
\hline SFA & $8 \cdot 9$ & $11 \cdot 9$ & $5 \cdot 9$ & $12 \cdot 9$ & $8 \cdot 4$ & & & & \\
\hline MUFA & $12 \cdot 1$ & $12 \cdot 8$ & $7 \cdot 4$ & $17 \cdot 2$ & $10 \cdot 9$ & & & & \\
\hline Oleic acid & $11 \cdot 2$ & $11 \cdot 7$ & $6 \cdot 8$ & $15 \cdot 8$ & $10 \cdot 0$ & & & & \\
\hline PUFA & $4 \cdot 1$ & $4 \cdot 2$ & $2 \cdot 8$ & $6 \cdot 1$ & $4 \cdot 0$ & & & & \\
\hline Linoleic acid & $3 \cdot 4$ & $3 \cdot 4$ & $2 \cdot 3$ & $5 \cdot 1$ & $3 \cdot 3$ & & & & \\
\hline Linolenic acid & 0.5 & 0.5 & $0 \cdot 3$ & $0 \cdot 7$ & 0.5 & & & & \\
\hline Carbohydrates & $57 \cdot 7$ & $48 \cdot 9$ & $68 \cdot 8$ & $47 \cdot 1$ & $58 \cdot 9$ & & & & \\
\hline Fibre $(\mathrm{g} / 1000 \mathrm{~kJ})$ & $3 \cdot 2$ & $2 \cdot 8$ & $2 \cdot 9$ & $2 \cdot 4$ & $4 \cdot 5$ & & & & \\
\hline \multicolumn{10}{|l|}{ Total daily energy intake (kJ) } \\
\hline \multicolumn{10}{|l|}{ Men } \\
\hline Mean & $11792 \cdot 6$ & $15336 \cdot 5$ & $18542 \cdot 2$ & $15121 \cdot 4$ & $15355 \cdot 7$ & & & & \\
\hline SD & $3677 \cdot 7$ & $5934 \cdot 6$ & $4432 \cdot 5$ & $5863 \cdot 9$ & $4912 \cdot 9$ & & & & \\
\hline \multicolumn{10}{|l|}{ Women } \\
\hline Mean & $9970 \cdot 5$ & $12301 \cdot 8$ & $16244 \cdot 4$ & $13032 \cdot 7$ & $12228 \cdot 6$ & & & & \\
\hline SD & $3038 \cdot 4$ & $4846 \cdot 3$ & $4126 \cdot 7$ & $4902 \cdot 4$ & $3986 \cdot 1$ & & & & \\
\hline Number of subjects & 476 & 206 & 55 & 141 & 174 & 52 & & 52 & 25 \\
\hline
\end{tabular}

*Symbols $+(-)$ describe the variation above (below) the mean expected intake: $+(-)$, by $<0.5$ standard deviation units (sDu); $++(--)$, by $0.5-1.0 \mathrm{sDu}$; $+++(---)$, by $1 \cdot 0-1 \cdot 5 \mathrm{sDu} ;++++(----)$, by $>1.5 \mathrm{sDu}$.

tThe cluster analysis was based on the standardised residuals of the linear regression analysis of each nutrient $v$. total energy intake (except alcohol) within gender.

by the highest intake of refined-grain products (bread, rice and pasta), thus containing more starch and substantially less dietary fibre. This group had the highest-energy diet: the mean daily energy intake was $18542 \cdot 2 \mathrm{~kJ}$ among men and $16244 \cdot 4 \mathrm{~kJ}$ among women.

4. Vegetal/fat pattern: This cluster consisted of the largest consumers of olive oil and, at the same time, fat sauces made with seed oil and/or butter. The people in this group also had the highest intake of dry fruits. Their diet was the highest in fat $(38.4 \% \mathrm{E})$ of all types, particularly unsaturated fat: $17 \cdot 2 \% \mathrm{E}$ from MUFA and $6 \cdot 1 \% \mathrm{E}$ from PUFA. It was also relatively poor in minerals and vitamins, except for vitamin $\mathrm{E}$.

5. Vitamin/fibre pattern: The subjects in this cluster consumed the largest amounts of vegetables, legumes 
and especially fruit. Their diet was very rich in vitamins and minerals, and also contained the largest amount of fibre $(4.5 \mathrm{~g} / 1000 \mathrm{~kJ})$. It had a moderately low fat content $(25 \cdot 2 \% \mathrm{E})$ and a slightly high carbohydrate content $(58 \cdot 9 \% \mathrm{E})$.

K-means clustering generated an ANOVA table showing $F$ tests for each variable (nutrient intake), with the magnitude of the $F$ values indicating how well the respective nutrients discriminated between clusters. Among the macronutrients, starch, animal protein, fibre and saturated fat were those most helpful in forming and differentiating the clusters; among the micronutrients, they were $\mathrm{K}$, vitamins $\mathrm{C}$ and $\mathrm{B}_{6}$ and $\beta$-carotene (the highest values were found in the vitamin/fibre group and the lowest in the starch and vegetal/fat clusters; data not shown).

\section{Prevalence of metabolic syndrome and associated factors}

The subjects in the starch group showed the highest adjusted prevalence of metabolic syndrome: $35.9 \%$ (Table 3). In comparison with the common group, the odds ratio for metabolic syndrome was $1 \cdot 8$ (95\% CI 1.0, 3.4): i.e. an $80 \%$ greater likelihood of having the syndrome. The second highest prevalence rate was in the animal products group (29.5\%), followed by the common diet (23.6\%), vitamin/fibre (19.9\%) and vegetal/fat groups (18.9\%). These differences were probably because the greatest prevalence of high TAG levels $(41.9 \%)$ was in the starch group and the greatest prevalence of impaired fasting glucose levels $(38 \cdot 1 \%)$ was in the animal products group. The starch group also showed the greatest prevalence of abdominal obesity $(30 \cdot 6 \%)$, followed by the animal products groups $(26.9 \%)$; the lowest prevalence $(17.5 \%)$ was in the vitamin/fibre group.

Among the normal-weight subjects, the prevalence of metabolic syndrome was about 3\% in all of the groups except for the vitamin/fibre group ( $0 \cdot 8 \%)$, which was due to the fact that they had the lowest prevalence of both abdominal obesity and high blood pressure. Although of normal weight, $9 \cdot 8 \%$ of the subjects in the starch group had a large waist circumference and $70 \cdot 1 \%$ of them had altered blood pressure. The animal products group had the highest prevalence of impaired fasting glucose levels $(20 \cdot 1 \%)$.

Among the overweight subjects, the prevalence of the syndrome rose to about $20 \%$ in the common, animal products and vitamin/fibre groups; in the vegetal/fat group, it was only $14 \cdot 8 \%$, much lower than the $36 \cdot 2 \%$ in the starch group. This difference was due to the worse lipid profile in the starch group.

Among the subjects classified as obese on the basis of their BMI values, $85 \cdot 2 \%$ of the subjects in the vitamin/ fibre group had a large waist circumference, but this was less than the $100.0 \%$ in the starch group. The obese subjects in the starch and animal products groups had the greatest prevalence of dyslipidaemia (high TAG and low HDL-C levels), and about $50 \%$ of the latter had impaired fasting glucose levels compared with $21.4 \%$ in the vita$\mathrm{min} /$ fibre cluster. The prevalence of metabolic syndrome among the obese was $73.2 \%$ in the starch group and $72.6 \%$ in the animal/products group, which contrasted with $46.0 \%$ in the common group, $43.5 \%$ in the vegetal/ fat group and $36 \cdot 3 \%$ in the vitamin/fibre group.

In order to quantify the relationship between dietary patterns and obesity status and their reciprocal influence on the association with the prevalence of metabolic syndrome, we used a logistic regression model which included also a dichotomous variable $\left(B M I \geq 30 \cdot 0 \mathrm{~kg} / \mathrm{m}^{2}\right)$ for obesity and a term for interaction between obesity and cluster groups. The estimated adjusted OR (95\% CI) for metabolic syndrome associated with obesity were $4 \cdot 0$ $(2 \cdot 4,6 \cdot 8)$ in the common pattern, $12 \cdot 6(5 \cdot 8,27 \cdot 3)$ in the animal products group, $9 \cdot 1(2 \cdot 0,42 \cdot 3)$ in the starch group, $5 \cdot 9(2 \cdot 2,15 \cdot 6)$ in the vegetal/fat group and $3 \cdot 3(1 \cdot 3,8 \cdot 1)$ in the vitamin/fibre cluster (data not shown).

\section{Discussion}

We found that the people in the starch group, who consumed a very-low-fat, high-carbohydrate diet, had the worst metabolic profile (particularly more dyslipidaemia and abdominal obesity) and the highest prevalence of metabolic syndrome (36\%). Their diet was rich in refinedgrain products, which have been found to be positively associated with metabolic syndrome in other studies ${ }^{(16,17)}$. Carbohydrate-induced atherogenic dyslipidaemia (higher TAG and lower HDL-C levels) is one of the most controversial and important issues in nutritional public health $^{(18)}$, and the fact that low-fat diets are often rich in carbohydrates has raised questions concerning the wisdom of institutional recommendations advocating a reduction in dietary fat intake as a means of treating or preventing $\operatorname{CVD}^{(19,20)}$.

With regard to dietary fat, there is growing consensus concerning the beneficial effects of MUFA and/or PUFA in terms of preventing diabetes and $\mathrm{CVD}^{(21-24)}$, but the detrimental effect of SFA is still controversial ${ }^{(25,26)}$. In our study, the highest total fat intake was found in the vegetal/fat group, followed by the animal products group. SFA content was similarly high in these two groups, but the diet of the subjects in the vegetal/fat group had a higher proportion of unsaturated fats. These subjects had one of the best metabolic profiles and the lowest prevalence of metabolic syndrome (18.9\%), whereas the animal products group showed one of the worst metabolic profiles (at least among the obese), particularly in terms of plasma lipid and fasting glucose levels, and it had the second highest prevalence of metabolic syndrome (29.5\%). Two factors may help interpret this finding: (i) the different sources of SFA in the 


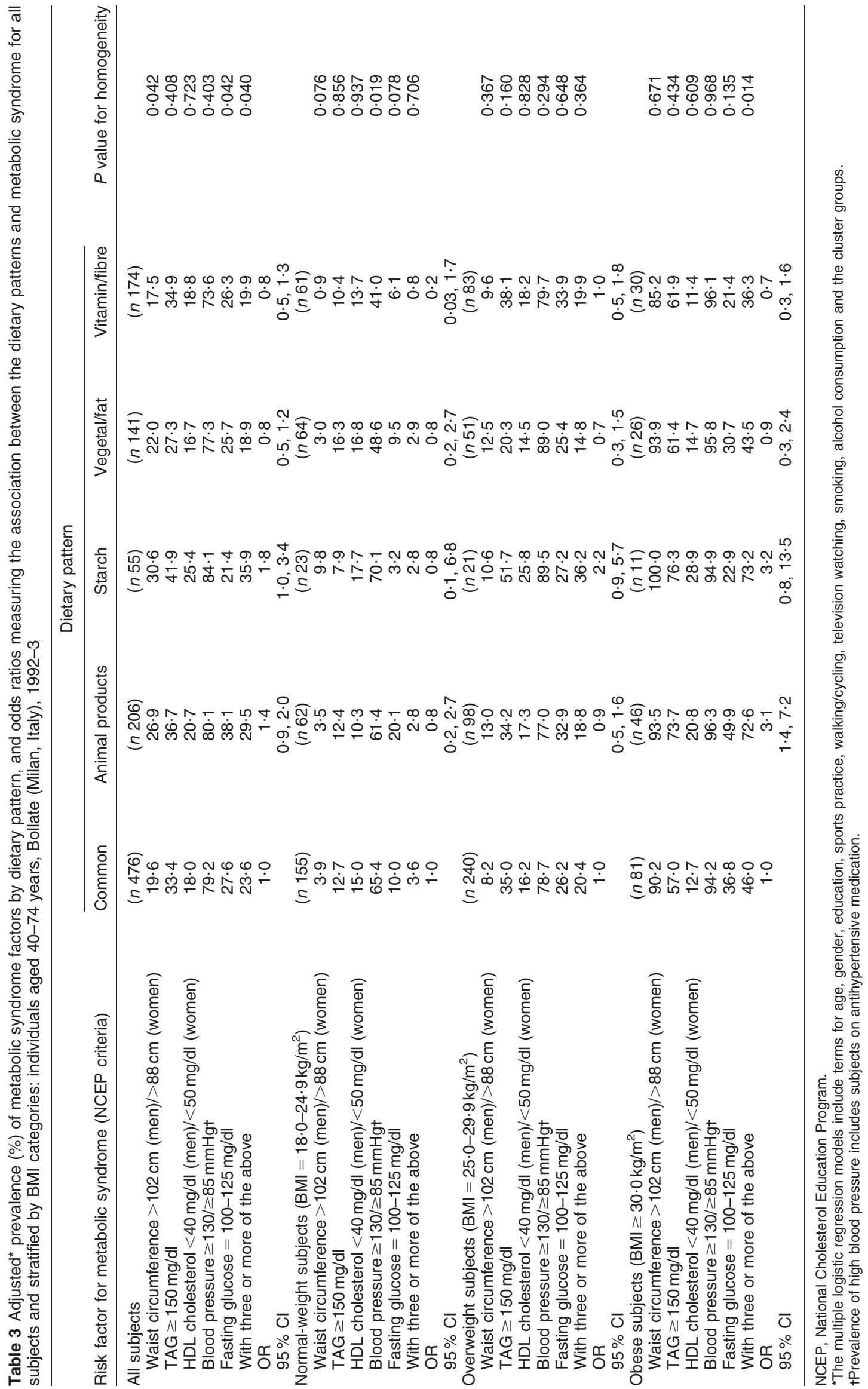


two diets, as it has been shown that different types of SFA have different functions and different metabolic effects $^{(27)}$; and (ii) the protective effect of unsaturated fats against the deleterious effect of SFA, as suggested by the results of some in vitro studies ${ }^{(28,29)}$.

The prevalence of impaired fasting glucose was lowest in the starch group (21.4\%); this value was quite comparable to those in the other clusters, but fairly smaller than the highest value $(38 \cdot 1 \%)$ in the animal products group. This result is in line with those obtained in metabolic studies, which have suggested that subjects with higher-fat diets containing a higher proportion of saturated fat are more prone to develop disturbances in glucose metabolism than subjects with lower intakes of $\mathrm{fat}^{(30)}$. A high-fat, low-carbohydrate diet has been found to induce insulin resistance in healthy men ${ }^{(31)}$ and to be associated with the onset of diabetes ${ }^{(32)}$, whereas a diet with a high ratio of polyunsaturated to saturated fatty acids (P/S) has been shown to improve cellular response to insulin compared with a low-P/S diet in normal and diabetic rats ${ }^{(33)}$. Moreover, a number of studies have shown that plasma glucose is not associated with carbohydrate intake in healthy adults ${ }^{(34,35)}$ nor in patients with mild diabetes ${ }^{(36)}$.

The inherent limitations of our study are related to the possible inaccuracy of the dietary information and the fact that its cross-sectional nature precludes causal inference. The method we used for the dietary survey (the FFQ) has been commonly adopted in epidemiological studies to assess usual intake of foods and nutrients, and it is well known that some degree of inaccuracy is inherent to this approach. However, results from validation studies ${ }^{(37)}$ have been generally accepted as indicative of the ability of the FFQ to rank individuals appropriately according to nutrient intake. Furthermore, advantages of the food frequency method include reasonable cost and direct assessment of usual intake, avoiding imprecision that results from day-to-day variation in food choices.

In relation to the effect of SFA, it is interesting to note that a preliminary exploratory analysis based on the individual nutrients (and made before we adopted the patterns approach) found that SFA was not related to metabolic syndrome factors. This observation underlines one of the advantages of the patterns approach: it provides a comprehensive picture of the dietary context in which a nutrient is consumed. Our results suggest that the effect of a high SFA intake in a 'vegetal' context may be different from its effect in an 'animal protein' context.

As a whole, the prevalence of central obesity was highest in the starch group (30.6\%) whose members had also the most energy-rich diet. However, in spite of the similar energy contents of their diets, subjects in the animal products group had a prevalence of abdominal obesity of about $27 \%$ against the $17 \cdot 5 \%$ found in the vitamin/fibre cluster, suggesting that the type of diet is important to keep a healthy body shape. Another strong point of our study is that it was stratified by obesity status. Obesity is a key aetiological factor in the development of metabolic syndrome, and various studies suggest that it may mediate the effect of total and saturated fat intake on diabetes risk ${ }^{(38,39)}$. As obesity may mediate the deleterious effects of dietary factors, stratification is the most appropriate way to examine its role because adjusting for rather than stratifying by the factors that modify the role of independent variables underestimates the strength of the association ${ }^{(40)}$. In comparison with the animal products and starch groups, the prevalence of metabolic syndrome was lower in the vegetal/fat group and particularly in the vitamin/fibre group, and these differences were more marked among the obese subjects. These findings are in line with those of other studies which showed that the beneficial effects of PUFA on CVD risk ${ }^{(41)}$ and of dietary fibre on insulin resistance ${ }^{(42)}$ are greatest among the overweight and obese. The fact that these beneficial effects are greater in obese subjects is important because it suggests that, even in the case of failure to achieve weight loss, diet can reduce obesity-related risk factors for CVD.

Obesity status influenced variation in the frequency of the metabolic syndrome factors across dietary clusters in different ways. The prevalence of high TAG levels increased with obesity status in all groups, but was particularly high in the starch cluster and also in the animal products group. The prevalence of low HDL-C increased with obesity only among subjects reporting the starch or animal products diet, while it remained quite unchanged in the common, vegetal/fat and vitamin/fibre groups. The prevalence of high blood pressure levels seemed influenced by dietary habits particularly among the normalweight subjects, with the lowest value in the vitamin/fibre group followed by the vegetal/fat cluster. Among overweight and obese subjects the prevalence of high blood pressure was similarly high in all dietary groups. From the analysis of the interaction between obesity and dietary pattern, our results show that dietary habits can modify the frequency of metabolic complications associated with obesity. The differences seem particularly due to the greater deterioration associated with obesity of both the lipid profile (in the starch and animal products groups) and the glycaemic profile (in the animal products group) when compared with the other clusters.

One characteristic of the animal products group is the high dietary content of animal protein. Some studies have found a direct relationship between the intake of red meat and the risk of $\mathrm{CVD}^{(43,44)}$, and others have shown that frequent consumption of processed meat increases the risk of diabetes ${ }^{(38,45)}$. It is particularly interesting to consider the role of $\mathrm{Fe}$ as studies have shown that a higher intake of haem Fe (derived from animal products) is associated with an increased risk of both CVD and diabetes $^{(46-48)}$, whereas no association has been found in 
the case of non-haem Fe (which is rich in the vitamin/ fibre pattern). Furthermore, it is well known that the intake of animal foods is the most important dietary determinant of the Fe status of a population, and serum ferritin has not only been found to be positively associated with metabolic syndrome ${ }^{(49)}$, but also proposed as a marker of insulin resistance syndrome ${ }^{(50)}$.

The characteristics of the diets in the vitamin/fibre group (rich in fruits and vegetables) and vegetal/fat group (rich in olive oil and nuts) combine the typical features of the Mediterranean diet: a high intake of unsaturated fats, vitamin $\mathrm{E}$, fibre, minerals and other antioxidant vitamins. It is thought that oxidative stress plays a role in the pathophysiology of diabetes ${ }^{(51)}$ and $\mathrm{CVD}^{(52)}$, and it has been found that adults with metabolic syndrome have suboptimal concentrations of a number of antioxidants, which may thus partially explain their increased risk of developing diabetes and $\mathrm{CVD}^{(53)}$. Vitamins $\mathrm{E}, \mathrm{A}$ and $\mathrm{C}$ and carotenoids are well-known antioxidants, and it has been found that virgin olive oil is beneficial in preventing oxidative processes ${ }^{(54)}$. Consequently, the beneficial effects of such dietary characteristics may be due to their role in preserving antioxidant status. One recent randomised trial has found that Mediterranean diets supplemented with olive oil or nuts have beneficial effects on cardiovascular risk factors in comparison with low-fat diets ${ }^{(55)}$. Furthermore, another nutrient common to the vitamin/fibre and vegetal/fat patterns is $\mathrm{Mg}$, which has been consistently found to be inversely associated with the prevalence and incidence of metabolic syndrome ${ }^{(56-58)}$. Unfortunately, our data do not include $\mathrm{Mg}$, but we know that nuts and vegetables are important sources of it.

In conclusion, the present results, showing the highest prevalence of metabolic syndrome in the starch group, support already compelling evidence about the deleterious effects of a very-low-fat diet rich in refined carbohydrates on lipid profile, particularly of overweight and obese subjects. Subjects in the animal products cluster, whose diet was rich in animal protein and fats, had the second highest prevalence of metabolic syndrome with the worst glycaemic profile. The results of our study also confirm the beneficial effects of diets rich in unsaturated fats, fruits and vegetables, probably due to their role in preserving antioxidant status, and suggest that rather than putting limits on the intake of total and saturated fat, greater attention should be paid to its sources - with the use of vegetable sources being recommended. The prevalence of metabolic syndrome was the lowest in the vegetal/fat group and vitamin/fibre group, markedly so among obese subjects. Since obesity is a key aetiological factor in the development of metabolic syndrome, the maintenance of normal body weight should be a primary goal in preventing it. However, even if this objective is not achieved, the adoption of beneficial dietary habits is important for preserving a healthy metabolic profile.

\section{Acknowledgements}

Conflict of interest declaration: There are no conflicts of interest. Sources of funding: The work was supported by research programme grant funding from the National Research Council (Italy) in the ambit of the Project Prevention and Control of Disease Factors (FATMA). Author contributions: A.N. designed the protocol, supervised the execution of the study and collaborated in writing the manuscript. M.L.C.L. did the statistical analysis and wrote the manuscript.

\section{References}

1. Grundy SM (2006) Metabolic syndrome: connecting and reconciling cardiovascular and diabetes worlds. J Am Coll Cardiol 47, 1093-1100.

2. Kelley DE (2003) Sugars and starch in the nutritional management of diabetes mellitus. Am J Clin Nutr 78, Suppl., 858S-864S.

3. Schulze MB \& Hu FB (2004) Dietary approaches to prevent the metabolic syndrome: quality versus quantity of carbohydrates. Diabetes Care 27, 613-614.

4. Weinberg SL (2004) The diet-heart hypothesis: a critique. J Am Coll Cardiol 43, 731-733.

5. Baxter AJ, Coyne T \& McClintock C (2006) Dietary patterns and metabolic syndrome - a review of epidemiologic evidence. Asia Pac J Clin Nutr 15, 134-142.

6. Nicolosi A (1997) Le indagini di popolazione sulla prevalenza delle principali malattie oculari in Italia. In L'epidemiologia oftalmica in Italia, pp. 43-70 [L Cerulli, M Miglior and $\mathrm{F}$ Ponte, editors]. Roma: INC.

7. Leite MLC, Nicolosi A, Firmo JOA \& Lima-Costa MF (2007) Features of metabolic syndrome in non-diabetic Italians and Brazilians: a discriminant analysis. Int J Clin Pract 61, 32-38.

8. Leite MLC \& Nicolosi A (2006) Lifestyle correlates of anthropometric estimates of body adiposity in an Italian middle-aged and elderly population: a covariance analysis. Int J Obes (Lond) 30, 926-934.

9. Willett WC (editor) (1998) 1980 Nurses' Health Study Dietary Questionnaire; Appendix 5-1. In Nutritional Epidemiology, 2nd ed., pp. 95-97. New York: Oxford University Press.

10. Salvini S, Parpinel M, Gnagnarella P, Maisonneuve P \& Turrini A (1998) Banca dati di composizione degli alimenti per studi epidemiologici in Italia. Milano: Istituto Europeo di Oncologia.

11. Willett WC \& Stampfer MJ (1998) Implications of total energy intake for epidemiologic analysis. In Nutritional Epidemiology, 2nd ed., pp. 273-301 [WC Willett, editor]. New York: Oxford University Press.

12. Jobson JD (1992) Applied Multivariate Data Analysis. vol. II: Categorical and Multivariate Methods. New York: Springer-Verlag.

13. National Heart Lung and Blood Institute (2001) Third Report of the Expert Panel on Detection, Evaluation, and Treatment of the High Blood Cholesterol in Adults (Adult Treatment Panel III): Executive Summary. http://www. nhlbi.nih.gov/guidelines/cholesterol/atp_iii.htm (accessed December 2008).

14. The Expert Committee on the Diagnosis and Classification of Diabetes Mellitus (2003) Follow-up report on the diagnosis of diabetes mellitus. Diabetes Care 26, 3160-3167.

15. Homer DW \& Lemeshow S (2000) Applied Logistic Regression, 2nd ed. New York: Wiley. 
16. Sahyoun NR, Jacques PF, Zhang XL, Juan W \& McKeown NM (2006) Whole-grain intake is inversely associated with the metabolic syndrome and mortality in older adults. $A m J$ Clin Nutr 83, 124-131.

17. Esmaillzadeh A, Mirmiran P \& Azizi F (2005) Whole-grain consumption and the metabolic syndrome: a favorable association in Tehranian adults. Eur J Clin Nutr 59, 353-362.

18. Parks EJ \& Hellerstein MK (2000) Carbohydrate-induced hypertriacylglycerolemia: historical perspective and review of biological mechanisms. Am J Clin Nutr 71, 412-433.

19. Jeppesen J, Schaaf P, Jones C, Zhou M-Y, Chen Y-DI \& Reaven GM (1997) Effects of low-fat, high-carbohydrate diets on risk factors for ischemic heart disease in postmenopausal women. Am J Clin Nutr 65, 1027-1033.

20. Abbasi F, McLaughli T, Lamendola C, Kim HS, Tanaka A, Wang T, Nakajima K \& Reaven GM (2000) High carbohydrate diets, triglyceride-rich lipoproteins, and coronary heart disease risk. Am J Cardiol 85, 45-48.

21. Meyer KA, Kushi LH, Jacobs DR \& Folson AR (2001) Dietary fat and incidence of type 2 diabetes in older Iowa women. Diabetes Care 24, 1528-1535.

22. Ros E (2003) Dietary cis-monounsaturated fatty acids and metabolic control in type 2 diabetes. Am J Clin Nutr $\mathbf{7 8}$, Suppl., 617S-625S.

23. Kris-Etherton PM (1999) Monounsaturated fatty acids and risks of cardiovascular disease. Circulation 100, 1253-1258.

24. Kris-Etherton PM, Hecker KD \& Binkoski AE (2004) Polyunsaturated fatty acids and cardiovascular health. Nutr Rev 62, 414-426.

25. Feskens EJM (2001) Can diabetes be prevented by vegetable fat? Diabetes Care 24, 1517-1518.

26. Golomb BA (1998) Dietary fats and heart disease - dogma challenged? J Clin Epidemiol 51, 461-464.

27. German JB \& Dillard CJ (2004) Saturated fats: what dietary intake? Am J Clin Nutr 80, 550-559.

28. Maedler K, Oberholzer J, Bucher P, Spinas GA \& Donath MY (2003) Monounsaturated fatty acids prevent the deleterious effects of palmitate and high glucose on human pancreatic $\beta$-cell turnover and function. Diabetes 52, 726-733.

29. Busch AK, Gurisik E, Cordery DV, Sudlow M, Denyer GS, Laybutt DR, Hughes WE \& Biden TJ (2005) Increased fatty acid desaturation and enhanced expression of stearoyl coenzyme A desaturase protects pancreatic $\beta$-cells from lipoapoptosis. Diabetes 54, 2917-2924.

30. Lichtenstein AH \& Schwab US (2000) Relationship of dietary fat to glucose metabolism. Atherosclerosis 150, 227-243.

31. Bisschop PH, de Metz J, Ackermans MT, Endert E, Pijl H, Kuipers F, Meijer AJ, Sauerwein HP \& Romijn JA (2001) Dietary fat content alters insulin-mediated glucose metabolism in healthy men. Am J Clin Nutr 73, 554-559.

32. Marshall JA, Hamman RF \& Baxter J (1991) High-fat, lowcarbohydrate diet and the etiology of non-insulin-dependent diabetes mellitus: The San Luis Valley Diabetes Study. Am J Epidemiol 134, 590-603.

33. Field CJ, Ryan EA, Thomson AB \& Clandinin MT (1990) Diet fat composition alters membrane phospholipid composition, insulin binding, and glucose metabolism in adipocytes from control and diabetic animals. J Biol Chem 265, 11143-11150.

34. Yang EJ, Kerver JM, Park YK, Kayitsinga J, Allison DB \& Song WO (2003) Carbohydrate intake and biomarkers of glycemic control among US adults: the third National Health and Nutrition Examination Survey (NHANES III). Am J Clin Nutr 77, 1426-1433.
35. Coulston AM, Liu GC \& Reaven GM (1983) Plasma glucose, insulin and lipid responses to high-carbohydrate low-fat diets in normal humans. Metabolism 32, 52-56.

36. Garg A, Grundy SM \& Unger RH (1992) Comparison of effects of high and low carbohydrate diets on plasma lipoproteins and insulin sensitivity in patients with mild NIDDM. Diabetes 41, 1278-1285.

37. Willett WC \& Lenart E (1998) Reproducibility and validity of food-frequency questionnaires. In Nutritional Epidemiology, 2nd ed., pp. 101-147 [WC Willett, editor]. New York: Oxford University Press.

38. Mayer-Davis EJ, Monaco JH, Hoen HM, Carmichael S, Vitolins MZ, Rewers MJ, Haffner SM, Ayad MF, Bergman RN \& Karter AJ (1997) Dietary fat and insulin sensitivity in a triethnic population: the role of obesity. The Insulin Resistance Atherosclerosis Study (IRAS). Am J Clin Nutr 65, 79-87.

39. van Dam RM, Willett WC, Rimm EB, Stampfer MJ \& Hu FB (2002) Dietary fat and meat intake in relation to risk of type 2 diabetes in men. Diabetes Care 25, 417-424.

40. Marchall JA \& Bessesen DH (2002) Dietary fat and the development of type 2 diabetes. Diabetes Care 25, 620-622.

41. Oh K, Hu FB, Manson JE, Stampfer MJ \& Willett WC (2005) Dietary fat intake and risk of coronary heart disease in women: 20 years of follow-up of the Nurses' Health Study. Am J Epidemiol 161, 672-679.

42. McKeown NM, Meigs JB, Liu S, Saltzman E, Wilson PW \& Jacques PF (2004) Carbohydrate nutrition, insulin resistance, and the prevalence of the metabolic syndrome in the Framingham Offspring Cohort. Diabetes Care 27, $438-546$.

43. Gramenzi A, Gentile A, Fasoli M, Negri E, Parazzini F \& La Vecchia C (1990) Association between certain foods and risk of acute myocardial infarction in women. BMJ 300, $771-773$.

44. Hu FB, Stampfer MJ, Manson JE, Ascherio A, Colditz GA, Speizer FE, Hennekens CH \& Willett WC (1999) Dietary saturated fats and their food sources in relation to the risk of coronary heart disease in women. Am J Clin Nutr $\mathbf{7 0}$, 1001-1008.

45. Schulze MB, Manson JE, Willett WC \& Hu FB (2003) Processed meat intake and incidence of type 2 diabetes in younger and middle-aged women. Diabetologia $\mathbf{4 6}$, $1465-1473$.

46. Ascherio A, Willett WC, Rimm EB, Giovannucci EL \& Stampfer MJ (1994) Dietary iron intake and risk of coronary disease among men. Circulation 89, 969-974.

47. van der A DL, Peeters PHM, Grobbee DE, Marx JJM \& van der Schouw YT (2004) Dietary haem iron and coronary heart disease in women. Eur Heart J 26, 257-262.

48. Rajpathak S, Ma J, Manson J, Willett WC \& Hu FB (2006) Iron intake and the risk of type 2 diabetes in women: a prospective cohort study. Diabetes Care 29, 1370-1376.

49. Megan J, Clark JM \& Guallar E (2004) Serum ferritin and risk of the metabolic syndrome in US adults. Diabetes Care 27, 2422-2428.

50. Fernandez-Real JM, Ricart-Engel W, Arroyo E, Balanca R, Casamitjana-Abella R, Cabrero D, Fernandez-Castaner M \& Soler J (1998) Serum ferritin as a component of the insulin resistance syndrome. Diabetes Care 21, 62-68.

51. Maritim AC, Sanders RA \& Watkins JB 3rd (2003) Diabetes, oxidative stress, and antioxidants: a review. J Biochem $\mathrm{Mol}$ Toxicol 17, 24-38.

52. Molavi B \& Mehta JL (2004) Oxidative stress in cardiovascular disease: molecular basis of its deleterious effects, its detection, and therapeutic considerations. Curr Opin Cardiol 19, 488-493.

53. Ford ES, Mokdad AH, Giles WH \& Brown DW (2003) The metabolic syndrome and antioxidant concentrations: 
findings from the third National Health and Nutrition Examination Survey. Diabetes 52, 2346-2352.

54. Marrugat J, Covas MI, Fito M, Schroder H, Miro-Casas E, Gimeno E, Lopez-Sabater MC, dela Torre R \& Farre M (2004) Effects of differing phenolic content in dietary olive oils on lipids and LDL oxidation - a randomized controlled trial. Eur J Nutr 43, 140-147.

55. Estruch R, Martinez-Gonzalez MA, Corella D et al. (2006) Effects of a Mediterranean-style diet on cardiovascular risk factors: a randomized trial. Ann Intern Med 145, $1-11$.
56. Song Y, Ridker PM, Manson JE, Cook NR, Buring JE \& Liu S (2005) Magnesium intake, C-reactive protein, and the prevalence of metabolic syndrome in middle-aged and older US women. Diabetes Care 28, 1438-1444.

57. Guerrero-Romero F \& Rodriguez-Moran M (2006) Hypomagnesemia, oxidative stress, inflammation, and metabolic syndrome. Diabetes Metab Res Rev 22, 471-476.

58. He K, Liu K, Daviglus ML, Morris SJ, Loria CM, Van Horn L, Jacobs DR \& Savage PJ (2006) Magnesium intake and incidence of metabolic syndrome among young adults. Circulation 113, 1675-1682. 